\title{
Regulatory T Cell Heterogeneity in the Thymus: Impact on Their Functional Activities
}

\author{
Jérémy C. Santamaria, Alexia Borelli and Magali Irla* \\ Aix-Marseille University, CNRS, INSERM, CIML, Centre d'Immunologie de Marseille-Luminy, Marseille, France
}

Foxp3 ${ }^{+}$regulatory $\mathrm{T}$ cells (Treg) maintain the integrity of the organism by preventing excessive immune responses. These cells protect against autoimmune diseases but are also important regulators of other immune responses including inflammation, allergy, infection, and tumors. Furthermore, they exert non-immune functions such as tissue repair and regeneration. In the periphery, Foxp3 ${ }^{+}$Treg have emerged as a highly heterogeneous cell population with distinct molecular and functional properties. Foxp3 ${ }^{+}$ Treg mainly develop within the thymus where they receive instructive signals for their

OPEN ACCESS

Edited by:

Ajithkumar Vasanthakumar, Peter Doherty Institute for Infection and Immunity, Australia

Reviewed by:

Tom Sidwell,

California Institute of Technology, United States

Santiago Zelenay,

The University of Manchester, United Kingdom

*Correspondence:

Magali Irla

magali.irla@inserm.fr

Specialty section:

This article was submitted to

$T$ Cell Biology,

a section of the journal

Frontiers in Immunology

Received: 17 December 2020

Accepted: 25 January 2021

Published: 11 February 2021

Citation:

Santamaria JC, Borelli A and Irla M

(2021) Regulatory T Cell Heterogeneity in the Thymus: Impact

on Their Functional Activities.

Front. Immunol. 12:643153.

doi: 10.3389/fimmu.2021.643153 differentiation. Recent studies have revealed that thymic Treg are also heterogeneous with two distinct precursors that give rise to mature Foxp3 ${ }^{+}$Treg exhibiting non-overlapping regulatory activities characterized by a differential ability to control different types of autoimmune reactions. Furthermore, the thymic Treg cell pool is not only composed of newly developing Treg, but also contain a large fraction of recirculating peripheral cells. Here, we review the two pathways of thymic Treg cell differentiation and their potential impact on Treg activity in the periphery. We also summarize our current knowledge on recirculating peripheral Treg in the thymus.

Keywords: immune tolerance, regulatory $\mathrm{T}$ cells, thymus, thymic recirculation, regulatory $\mathrm{T}$ cell heterogeneity, autoimmune disorders

\section{INTRODUCTION}

$\mathrm{CD} 4^{+}$Foxp $^{+}$regulatory $\mathrm{T}$ cells (Treg) crucially maintain immune tolerance. These cells are endowed with the unique ability to protect from life-threatening autoimmune reactions and dampen inflammatory responses. The absence of Foxp $3^{+}$Treg in IPEX (Immune dysregulation, Polyendocrinopathy, Enteropathy, X-linked syndrome) patients, and scurfy mice results in a severe lymphoproliferation and multi-organ autoimmunity (1-4). Treg cells are also involved in numerous physio-pathological processes such as foeto-maternal tolerance, allergy, anti-tumoral immunity, tissue homeostasis, and repair $(5,6)$. This large array of functions implies a division of labor by several Treg subsets. This heterogeneity is illustrated by the central Treg (cTreg)/effector Treg (eTreg) dichotomy (7). cTreg are found in lymphoid organs and depend on IL-2, whereas eTreg populate non-lymphoid tissues and depend on TCR signals for their proliferation. Similarly to conventional $\mathrm{CD} 4^{+} \mathrm{T}$ helper (Th) cells, the cytokine microenvironment induces the polarization of Treg into Th1-, Th2-, Th17-, and follicular Treg (Tfr)-like cells, showing distinct chemokine receptor expression patterns (8). This polarization allows Treg to specifically antagonize their conventional $\mathrm{CD} 4^{+}$Th counterparts. 
The majority of Foxp $3^{+}$Treg develop in the thymus (tTreg) although conventional $\mathrm{CD}^{+} \mathrm{T}$ cells can also convert in the periphery into Foxp $3^{+}$Treg under certain conditions (pTreg) (9). Several precursors including CD $25^{+}$Foxp $3^{-}$cells, recent thymic emigrants (RTE) and FR4 ${ }^{\text {hi }} \mathrm{CD} 73^{\text {hi }}$ cells have been proposed to differentiate into $\mathrm{pTreg}$, which have both overlapping and unique TCR repertoire and functions compared to tTreg (9-17). Thymic development of Treg cells was initially suggested by seminal work during the 1960's describing generalized autoimmune manifestations in neonatal thymectomies, before day 3 but not later $(18,19)$. Further works demonstrated that suppressive $\mathrm{T}$ cells exerting a dominant tolerance develop during this neonatal period in the thymus and were called "regulatory T cells" (20-24). Thymic Treg cells represent only $\sim 2-3 \%$ of developing CD4 ${ }^{+}$ single positive (SP) thymocytes. Their development is driven by strong TCR stimulation coupled to the CD28 co-stimulatory signal. A third signal mediated by $\gamma$-chain cytokines promotes their survival and progression into a mature $\mathrm{CD} 25^{+}$Foxp $3^{+}$Treg stage (25).

Recent advances have revealed that thymic Treg constitute a more diverse and dynamic population than previously thought. Emerging evidences indicate that the phenotypically and functional diversity of Treg could be imprinted during their ontogeny in the thymus. In this review, we discuss our current knowledge on the two identified precursors leading to the development of mature Treg, showing distinct regulatory activities. We also highlight a new population of mature Treg recirculating from the periphery into the thymus.

\section{DISTINCT THYMIC FOXP3 ${ }^{+}$TREG SUBSETS GENERATED BY TWO DEVELOPMENTAL PATHWAYS}

T-cell fate decision toward clonal deletion (also called negative selection) or the diversion into the Treg or $\mathrm{T}$ conventional cell lineage is dictated by TCR affinity and/or avidity for selfpeptides presented by thymic antigen presenting cells [APC (26)]. The relative contributions of the different APC subsets such as medullary thymic epithelial cells (mTEC), cortical TEC (cTEC), $B$ cells, conventional, and plasmacytoid dendritic cells (DC) in T-cell fate decision remain poorly understood although bone marrow-derived APC and mTEC seem to play non-overlapping roles in shaping the TCR repertoire (27). The introduction of a cognate antigen in TCR transgenic mice leads to both clonal Tcell deletion and Treg induction, indicating that the diversion into the Treg cell lineage is also induced by the recognition of agonist self-peptide (28). Treg thus show a highly selfreactive TCR repertoire, distinct from conventional T cells, which contributes to their functional diversity (29-32). The prevailing paradigm of Treg development is based on the integration of signals mediated by TCR/CD28 stimulation and cytokine signaling. It relies on a "two-step model" in which strong agonist TCR signals in $\mathrm{CD}_{2} 5^{-}$Foxp $3^{-} \mathrm{CD} 4^{+}$SP thymocytes results in the induction of CD25 (also known as IL-2R $\alpha$ ) and thus in the development of $\mathrm{CD}_{25} 5^{+}$Foxp $3^{-}$Treg precursors (CD25 ${ }^{+}$TregP) (step one) (Figure 1). However, the TCR signal strength required to select Treg was described to be lower than that leading to clonal deletion of $\mathrm{CD}^{+}$SP thymocytes $(30,33)$. This could be due to a lower intrinsic TCR affinity or to the limited expression of the cognate antigen by APC, thus reducing multiple antigen encounters $(34,35)$. The CD28-CD80/86 costimulatory axis is also essential for Treg development from their precursor stage (36-38). This is well illustrated in $\mathrm{Cd} 28^{-/-}$and $C d 80^{-/-} \times$ Cd86-/- mice showing impaired generation of CD25 ${ }^{+}$TregP and a severe defect in mature Treg. Furthermore, the TCR signaling pathway in association with the CD28 co-stimulation signal drives the upregulation of tumor-necrosis factor receptor superfamily (TNFRSF) members such as GITR, OX40, and TNFR2 in CD25 ${ }^{+}$TregP (39). The CD28 co-stimulation in developing thymocytes has also been reported to induce Foxp3 expression (40).

The second step of Treg development that drives the maturation of $\mathrm{CD} 25^{+}$TregP into mature CD $25^{+}$Foxp $^{+}$Treg depends on $\gamma$-chain cytokines, in particular IL-2 and/or IL-15 signaling (Figure 1) (41-43). Mice deficient for the IL-2r $\gamma$ chain, which is shared by IL-2,-4,-7,-9,-15, and -21 receptors, lack this cell type $(42,44)$. However, mice deficient for IL-2 or IL-2r $\alpha$ display only half of Foxp3 ${ }^{+}$Treg, indicating that IL-2 plays a major role in Treg development (44). Furthermore, mice lacking the IL-2r $\beta$ chain, shared by IL- 2 and IL-15 receptors, were also found to almost lack mature Treg $(42,44,45)$. Accordingly, the generation of IL- $2 \times$ IL-15 double-deficient mice has revealed a similar Treg defect as that observed in $I l 2 r \beta^{-/-}$mice, indicating that IL-15 is also implicated in Treg cell development $(42,46,47)$. These two cytokines promote survival and thus rescue Treg from the pro-apoptotic effects of Foxp3 (48). In addition, the stimulation of GITR, OX40, or TNFR2 participates in this second step by enhancing the conversion of CD25 ${ }^{+}$TregP into mature Treg through an increase responsiveness to IL-2 (39).

Recent advances have shed new light on the cellular source of IL-2 and IL-15 cytokines. DC have been initially proposed to constitute a privileged developmental niche for Treg cell generation by providing both cognate self-antigens and IL-2 (49). However, this concept has been recently challenged. Although IL2 can be produced by thymic DC, the selective ablation of the Il2 gene in DC and T cells in the absence of IL-15 revealed that only IL-2 provided by T cells severely impairs Treg development (50). Accordingly, IL-2 production was more precisely assigned to selfreactive $\mathrm{CD} 4^{+}$thymocytes, including Treg precursors (51). These observations suggest that the size of the Treg cell population is regulated by self-reactive thymocytes through IL-2 production. In contrast to IL-2, IL-15 is provided by stromal cells, mainly TEC including cTEC and mTEC expressing both low and high levels of MHC class II molecules $(46,52,53)$.

A second developmental pathway has recently emerged based on the identification of another Treg precursor subset expressing low level of Foxp3 and lacking CD25 cell surface expression (Foxp3 $3^{\text {lo }}$ TregP) $(46,54)$. Similarly to CD25 ${ }^{+}$TregP, a substantial proportion of Foxp $3^{\text {lo }}$ TregP differentiates into mature Treg upon intrathymic transfer. These observations indicate that both $\mathrm{CD} 25^{+}$and Foxp $3^{\text {lo }}$ TregP contribute to the generation of the mature Treg pool. Foxp $3^{\text {lo }}$ TregP seems to depend on IL-15 for their survival, and then on IL-2 to fully differentiate into mature 


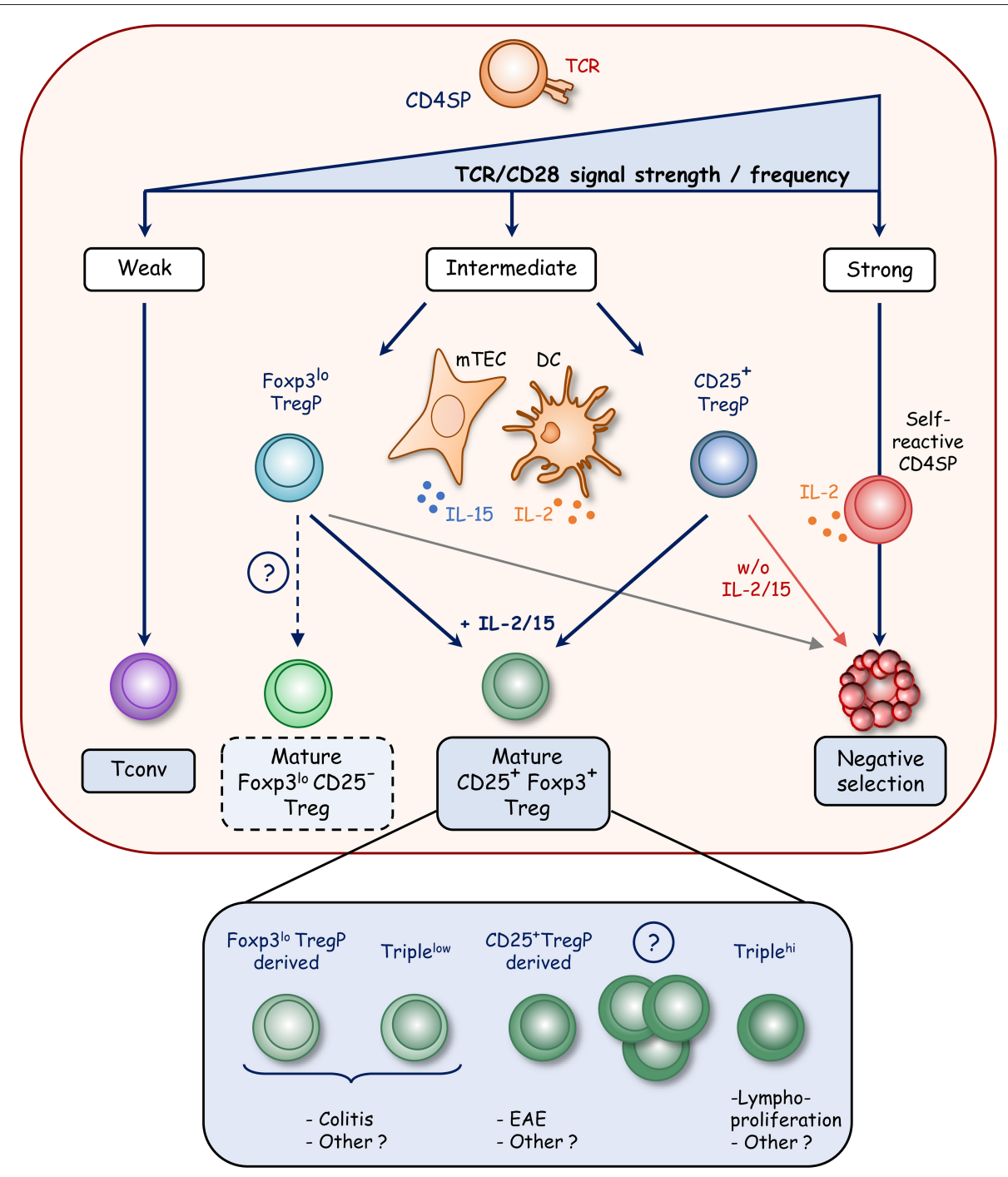

FIGURE 1 | Model of Foxp3 ${ }^{+}$Treg development in the thymus. During thymic development, strong TCR signals lead to clonal deletion of highly self-reactive CD4 ${ }^{+}$SP thymocytes whereas weak signals result in the generation of conventional T cells (Tconv). In contrast, intermediate TCR signals result in the diversion of CD4+ SP thymocytes into the Treg cell lineage with the development of two distinct precursors. CD25 ${ }^{+}$Treg precursors (CD25 ${ }^{+}$TregP) develop upon strong TCR signals that induce CD25 expression whereas Foxp3 $3^{\text {lo }}$ Treg precursors (Foxp3 $3^{\text {lo }}$ TregP) develop upon weaker TCR signals, which drive the upregulation of Foxp3. Further development of these two precursors requires survival signals mediated by $\gamma$ c cytokine signaling. IL-2 produced by DC and self-reactive CD4+ SP thymocytes and IL-15 produced by mTEC rescue Treg precursors from cell death and lead to mature CD25+Foxp3 ${ }^{+}$Treg development. Interestingly, mature CD25 ${ }^{+}$Foxp3 ${ }^{+}$Treg appear to have distinct functional properties according to the precursors from which they are derived. CD25-Foxp $3^{\text {lo }}$ cells also likely contain a subset of mature Treg

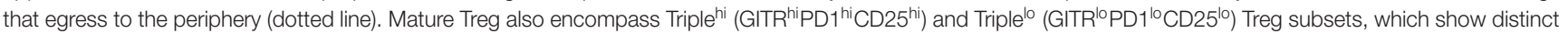
functional activities.

Treg cells whereas CD25 ${ }^{+}$TregP likely depend on IL-2 for their development. Treg cells are thus generated via two distinct developmental programs involving $\mathrm{CD} 25^{+}$and Foxp $3^{\text {lo }}$ TregP (54) (Figure 1). CD $25^{+}$TregP show a higher affinity for selfantigens than Foxp $3^{\text {lo }}$ TregP. Accordingly, these two precursors exhibit a distinct TCR repertoire and thus make unique contribution to the mature Treg TCR repertoire. Furthermore, they have distinct transcriptomes, regulated by different signaling pathways and enhancers. The NFкB signaling pathway and the Foxp3 regulatory element Cns 3 were found to be required for the development of Foxp $3^{\text {lo }}$ TregP but dispensable for CD $25^{+}$ TregP. Interestingly, although these two precursors can give rise to mature Treg, they have distinct functional capacities. Treg derived from $\mathrm{CD}_{2} 5^{+}$TregP protect from experimental autoimmune encephalomyelitis, whereas those derived from Foxp $3^{\text {lo }}$ TregP protect from T-cell induced colitis. These observations open new perspectives to treat autoimmune disorders by Tregcell based therapy, which is currently extremely promising in clinical trials (55). Moreover, single-cell transcriptomic analysis suggests the presence of CD25 $5^{+}$and Foxp $3^{\text {lo }}$ TregP in the human 
thymus (56), indicating conserved developmental pathways, although further investigations are required.

The discovery of these two Treg cell precursors raises the question about the existence of a common or a distinct pre-precursor. It has been recently proposed that $\mathrm{CD}^{+} \mathrm{GITR}^{+} \mathrm{CD} 122^{+} \mathrm{CD} 25^{-}$Foxp $^{-}$cells represent a Treg preprecursor population, which remains to be clearly established $(57,58)$. Furthermore, $\mathrm{CD} 25^{-} \mathrm{Foxp}^{\mathrm{lo}}$ cells seem to be at a more mature stage than $\mathrm{CD} 25^{+} \mathrm{Foxp}^{-}$cells based on their $\mathrm{CD} 24^{\mathrm{lo}} \mathrm{Qa} 2{ }^{\mathrm{hi}}$ phenotype or their "thymic age" measured by their green fluorescent protein (GFP) expression level using transgenic mice expressing GFP under the recombinationactivating gene 2 promoter (Rag2-GFP model) (59). These observations could be due to a later emergence of these cells during T-cell development or by the presence of mature developing Treg among this population as suggested by other experiments (60). In accordance with this latter hypothesis, a substantial fraction of RTE and functional peripheral Treg are CD25- Foxp $3^{+}$cells $(7,46,61)$. Thus, further investigations are required to better define the cellular composition of the $\mathrm{CD} 25^{-} \mathrm{Foxp}^{\text {lo }}$ compartment.

Two mature Treg cell subsets were also identified based on the expression level of CD25, GITR, and PD-1 and were defined as GITR $^{\text {lo }} \mathrm{PD}-1^{\text {lo }} \mathrm{CD} 25^{\text {lo }}$ (Triple ${ }^{\mathrm{lo}}$ ) and GITR ${ }^{\text {hi }} \mathrm{PD}-1^{\text {hi }} \mathrm{CD} 25^{\text {hi }}$ (Triple ${ }^{\text {hi }}$ ) cells (61). These cells develop within the thymus and show a distinct TCR repertoire with different affinities for self-antigens with Triple $^{\text {hi }}$ Treg being more self-reactive than Triple $^{\text {lo }}$ Treg. Interestingly, Triple ${ }^{\text {hi }}$ Treg control the lymphoproliferation in peripheral lymph nodes, suggesting an ability to protect against auto-immune disorders, whereas Triple ${ }^{\text {lo }}$ Treg limit the development of colitis by promoting the conversion of conventional $\mathrm{CD}^{+} \mathrm{T}$ cells into pTreg. Nevertheless, their respective relationship with $\mathrm{CD} 25^{+}$and Foxp $3^{\text {lo }}$ TregP remains to be established. Therefore, these recent advances on Treg development have revealed a developmentally regulated heterogeneity in the thymic Treg population (Figure 1). These findings thus indicate that the thymus generates multiple Treg subsets with non-overlapping regulatory activities.

\section{HETEROGENEITY AND FUNCTION OF RECIRCULATING THYMIC TREG CELLS}

Although thymic Treg were thought to represent a homogenous population of developing cells for a long time, several recent studies have described the presence of mature cells derived from the periphery or in retention upon their development in the thymus. The homing of mature peripheral Treg into the thymus was initially reported in the context of parabiosis experiments and lymphopenic mice $(62,63)$. The generation of Rag2-GFP mice was particularly useful to distinguish developing Rag2$\mathrm{GFP}^{+}$Treg and older Rag2-GFP ${ }^{-}$Treg (59). After positive selection, the expression of the Rag2 gene stops and GFP undergoes exponential decay with a half-life of $\sim 56 \mathrm{~h}$ (64). Using this model, a consequent fraction of thymic Treg were found to be Rag2-GFP ${ }^{-}$cells (65). It was later demonstrated that these cells contain peripheral Treg migrating back to their organ of origin
(Figure 2) $(66,67)$. Some Rag2-GFP ${ }^{-}$Treg can also correspond to resident cells that have never left the thymus, making more complex the heterogeneity of this mature Treg population (68). Interestingly, mature Rag2-GFP ${ }^{-}$Treg represent around half of the thymic Treg pool in 8 week-old B6 mice, and almost their totality in 6 month-old B6 mice, unraveling an age-dependent accumulation of these cells within the thymus $(66,68)$. These cells display an activated and effector phenotype, which is required for their migration into the thymus (69). Their trafficking is likely directed by CXCR4/CXCL12 and CCR6/CCL20 chemokine axes $(66,70)$. CCL20 is mainly produced by mTEC under the control of the transcription factor Aire (Autoimmune regulator), which is crucial for the establishment of T-cell tolerance (71). The CCR6/CCL20 axis could thus be responsible of the almost exclusive medullary localization of recirculating Treg $(69,70)$. It was recently described that the IL-18 stimulation of peripheral IL18R-expressing Treg allows the expression of CCR6 that favors their recirculation into the thymus (72). In addition to CCR6, CD73 was found to discriminate mature Rag2-GFP ${ }^{-}$Treg from newly produced Rag2-GFP ${ }^{+}$Treg $(54,69)$. Recirculating mature Treg can thus be identified as $\mathrm{CCR} 6^{+} \mathrm{CD} 73^{+}$in the absence of Rag2-GFP transgenic reporter mice (Figure 2).

However, is this recirculation an epiphenomenon or do these cells have a function in the thymus? The medullary localization, the effector phenotype and the accumulation of mature Rag2$\mathrm{GFP}^{-}$Treg during aging that occurs concomitantly with the reduced development of Rag2-GFP ${ }^{+}$Treg suggests a suppressive function of these cells. In line with this hypothesis, the addition of mature Treg either to fetal thymic organ cultures (FTOC) or adult thymic tissue slices inhibits de novo Treg production by consuming locally available IL-2 $(49,66)$. Accordingly, an increase in Treg development is observed if the amount of recirculating Treg is naturally (different mouse strains) or artificially (peripheral CD4 ${ }^{+}$T-cell depletion) diminished (69). Thus, the thymic Treg niche seems to be stable with age, but dynamic in its composition and regulated by the amount of mature Treg that repopulate the thymus. This feedback loop regulation of Treg production by recirculating cells has been recently challenged by observations made in Aire ${ }^{-/-}$,

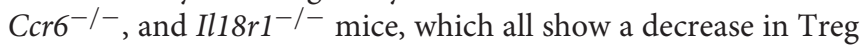
recirculation with no obvious impact on de novo generated Treg cells $(70,72)$. These observations could question the dynamic balance between developing and recirculating Treg. However, Treg recirculation is only partially abrogated in these mice and it cannot be excluded that the remaining recirculating mature Treg cells are able to inhibit Treg production. Furthermore, since numbers of $\mathrm{Aire}^{+}$mTEC were reported to influence antigen-mediated Treg selection, the expected stronger Treg development in Aire ${ }^{-/-}$mice could be hidden by impaired basal Treg induction, which was described in neonatal mice lacking recirculating Treg (73). Conversely, mice deficient for OPG (osteoprotegerin; encoded by Tnfrsf11b), the soluble decoy receptor for RANKL (receptor activator of nuclear factor- $\mathrm{KB}$ ligand; encoded by Tnfsf 11 ), which controls the development of Aire $^{+}$mTEC, show an increase Treg recirculation with no defect in de novo Treg production (74). Nevertheless, the strong inhibition by recirculating Treg in these mice could be 


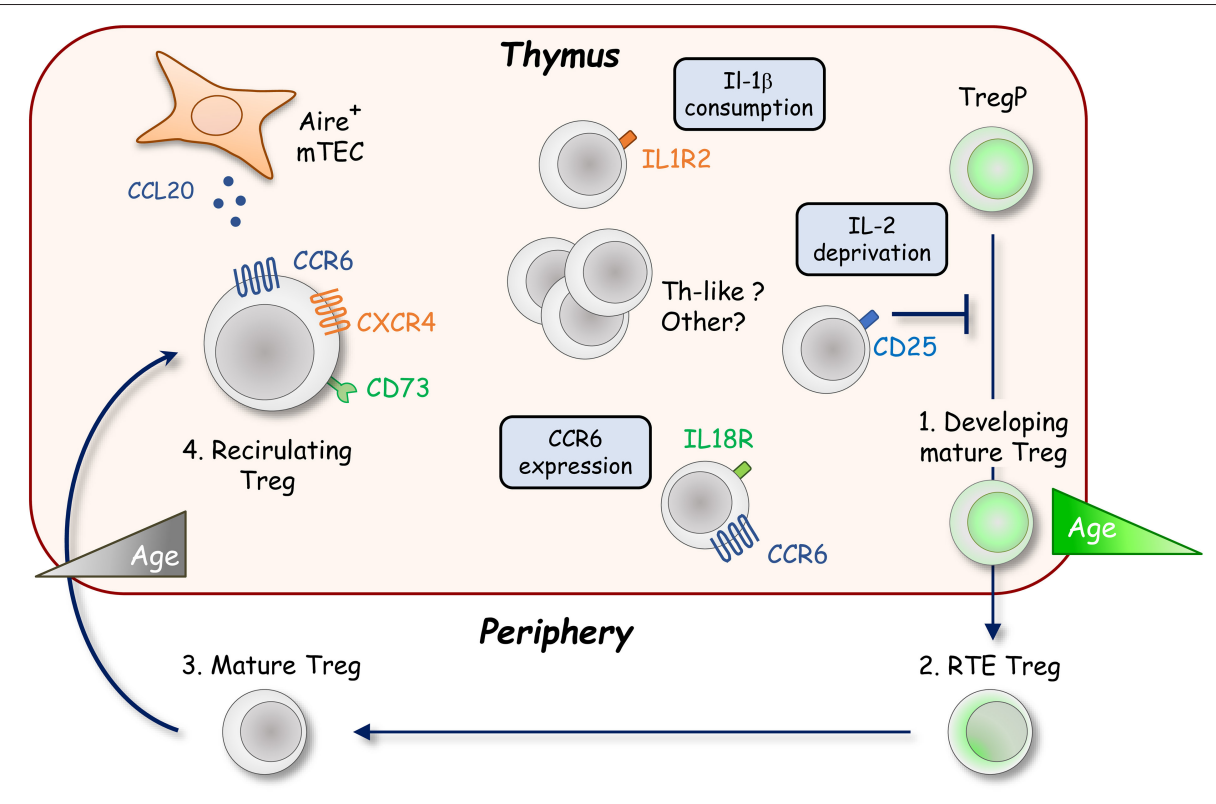

FIGURE 2 | Recirculation of peripheral Foxp3 ${ }^{+}$Treg into the thymus. The thymic Foxp3 ${ }^{+}$Treg population is not only composed of developing Rag2-GFP+ Treg (green cell) but also contains a large fraction of recirculating mature Rag2-GFP ${ }^{-}$Treg from the periphery showing an activated phenotype (gray cells). The recirculation of peripheral Treg likely depends on CCR6 and CXCR4 chemokine receptors. These cells mainly localize into the thymic medulla in response to the production of the CCR6 ligand, CCL20, by Aire ${ }^{+}$mTEC. Once in the thymus, recirculating CCR6 ${ }^{+} \mathrm{CD} 73^{+}$Treg inhibit the development of de novo CD25 $5^{+}$Foxp $3^{+}$Treg in an age dependent manner by IL-2 deprivation. Distinct subsets of recirculating Treg were recently described such as IL-1R2 ${ }^{+}$Treg that maintain Treg development by quenching IL-1 $\beta$ under inflammatory conditions. An IL-18R+ subset, endowed with a higher ability to recirculate into the thymus than their IL-18R- Treg counterparts, was also described. In this subset, IL-18 signaling likely promotes the thymic entry of peripheral Treg by upregulating CCR6 expression.

counterbalanced by an increased development of de novo Treg mediated by exacerbated Aire ${ }^{+}$mTEC numbers $(27,75-77)$. Further studies are definitely required to clarify the impact of peripheral Treg on de novo Treg production. The generation of transgenic mice either fully lacking recirculating Treg, or with adjustable amount of recirculating Treg into the thymus, is expected to clarify this issue.

Since Treg promote the homeostasis of several other tissues such as skeletal muscle, visceral adipose tissue, lung, central nervous system, and skin $(5,6)$, recirculating Treg could also participate in thymus homeostasis. In particular, the crosstalk with $\mathrm{CD}^{+}$SP thymocytes controls the development of Aire ${ }^{+}$ mTEC that are responsible for peripheral Treg re-entry into the thymus $(78,79)$. Since recirculating Treg express RANKL and that the development of Aire $^{+}$mTEC is mediated by the RANK-RANKL signaling pathway $(75,79-81)$, it would be of special interest to define whether recirculating Treg are in turn implicated in the regulation of Aire $^{+}$mTEC cellularity or other stromal cells throughout lifespan. In line with this hypothesis, excessive RANK signaling driven by activated $\mathrm{CD}^{+} \mathrm{T}$ cells has been reported to enhance Aire ${ }^{+}$ mTEC development and in fine promote the exhaustion of epithelial progenitors (82). Further investigations are required to evaluate the function of mature recirculating Treg in the thymus. One important step before is undoubtedly to better characterize the cell subsets that reside within the recirculating mature Treg compartment. Similarly to developing Treg, a heterogeneity is emerging among recirculating mature Treg. Two subsets, IL-18R ${ }^{-}$, and IL- $18 \mathrm{R}^{+}$cells, the latter showing molecular similarities with tissue-resident effector Treg, have been described (72). Based on the differential expression of the decoy receptor for the inflammatory cytokine IL-1, IL-1R2-, and $\mathrm{IL}-1 \mathrm{R} 2^{+}$recirculating Treg have been also reported with IL-1R2 ${ }^{+}$Treg protecting Treg development under inflammatory conditions by quenching IL-1 (83). Furthermore, the Triple ${ }^{\text {hi }}$ and Triple $^{\text {lo }}$ subsets described in the developing Treg compartment were also observed among recirculating Treg (61). However, the relationship between IL-18R ${ }^{-}, \mathrm{IL}_{-}-18 \mathrm{R}^{+}, \mathrm{IL}-1 \mathrm{R} 2^{-}, \mathrm{IL}-1 \mathrm{R} 2^{+}$, Triple $^{\text {hi }}$, and Triple ${ }^{\text {lo }}$ subsets in recirculating Treg remain to be determined. Interestingly, high-throughput RNA sequencing on the bulk of Rag2-GFP ${ }^{-}$Treg revealed a high expression for many genes specific of Th1-, Th2-, Th17-, Tfr-like Treg and markers found in adipose- and muscle-tissue Treg (Figure 2) (66). These observations suggest a greater heterogeneity in the Rag2$\mathrm{GFP}^{-}$Treg compartment than currently described. Single cell transcriptomic analysis of recirculating Treg is expected to shed new light on the composition of distinct effector cells that resides in this compartment. Interestingly, peripheral Treg also likely migrate back to the thymus in humans, indicative of a conserved mechanism. These cells, identified as $\mathrm{CD} 31^{-}$, a marker expressed by developing thymocytes and RTE and downregulated during peripheral maturation, display an activated and differentiated phenotype (66). Further investigations are now required to better understand human mature Treg heterogeneity and functionality. 


\section{CONCLUDING REMARKS}

Recent advances have highlighted an unsuspected heterogeneity in the thymic Treg cell population, including in developing and recirculating Treg. Given that at least two precursors give rise to several subsets of mature Foxp $3^{+}$Treg, with distinct abilities to suppress autoimmunity, it would be not surprising that a functional imprinting is acquired from Treg cell development in the thymus. Beyond the TCR repertoire, this imprinting could be driven in specific niches providing different molecular and cellular cues such as cytokines, TNFRSF signals, and APC subsets. A heterogeneity in the recirculating Treg compartment is also currently emerging, opening new interesting questions on their tissue origin and their respective roles in the thymic function. Furthermore, it remains to be determined whether different recirculating subsets could interact with distinct stromal cells and regulate the thymic selection, not only of Treg, but also of conventional and unconventional $\mathrm{T}$ cells. Moreover, recirculating Treg could participate to the homeostasis of the thymus similarly to their peripheral counterparts. Finally, future investigations aimed at deciphering the developmental pathways of specific

\section{REFERENCES}

1. Chatila TA, Blaeser F, Ho N, Lederman HM, Voulgaropoulos C, Helms C, et al. JM2, encoding a fork head-related protein, is mutated in X-linked autoimmunity-allergic disregulation syndrome. J Clin Invest. (2000) 106:R7581. doi: 10.1172/JCI11679

2. Bennett CL, Christie J, Ramsdell F, Brunkow ME, Ferguson PJ, Whitesell $\mathrm{L}$, et al. The immune dysregulation, polyendocrinopathy, enteropathy, Xlinked syndrome (IPEX) is caused by mutations of FOXP3. Nat Genet. (2001) 27:20-1. doi: 10.1038/83713

3. Wildin RS, Ramsdell F, Peake J, Faravelli F, Casanova JL, Buist N, et al. Xlinked neonatal diabetes mellitus, enteropathy and endocrinopathy syndrome is the human equivalent of mouse scurfy. Nat Genet. (2001) 27:1820. doi: $10.1038 / 83707$

4. Brunkow ME, Jeffery EW, Hjerrild KA, Paeper B, Clark LB, Yasayko S, et al. Disruption of a new forkhead/winged-helix protein, scurfin, results in the fatal lymphoproliferative disorder of the scurfy mouse. Nature. (2001) 27:68-73. doi: 10.1038/83784

5. Panduro M, Benoist C, Mathis D. Tissue tregs. Annu Rev Immunol. (2016) 34:609-33. doi: 10.1146/annurev-immunol-032712-095948

6. Sharma A, Rudra D. Emerging functions of regulatory $\mathrm{T}$ cells in tissue homeostasis. Front Immunol. (2018) 9:1-26. doi: 10.3389/fimmu.2018.00883

7. Smigiel KS, Richards E, Srivastava S, Thomas KR, Dudda JC, Klonowski $\mathrm{KD}$, et al. CCR7 provides localized access to IL-2 and defines homeostatically distinct regulatory $\mathrm{T}$ cell subsets. J Exp Med. (2014) 211:121-36. doi: 10.1084/jem.20131142

8. Cretney E, Kallies A, Nutt SL. Differentiation and function of Foxp3+ effector regulatory $\mathrm{T}$ cells. Trends Immunol. (2013) 34:74-80. doi: 10.1016/j.it.2012.11.002

9. Savage PA, Klawon DEJ, Miller CH. Regulatory T cell development. Annu Rev Immunol. (2020) 38:421-53. doi: 10.1146/annurev-immunol-100219-020937

10. Paiva RS, Lino AC, Bergman M-L, Caramalho Í, Sousa AE, Zelenay S, et al. Recent thymic emigrants are the preferential precursors of regulatory $\mathrm{T}$ cells differentiated in the periphery. Proc Natl Acad Sci USA. (2013) 110:64949. doi: 10.1073/pnas.1221955110

11. Schallenberg S, Tsai P-Y, Riewaldt J, Kretschmer K. Identification of an immediate Foxp3- precursor to Foxp3+ regulatory $\mathrm{T}$ cells in peripheral lymphoid organs of nonmanipulated mice. J Exp Med. (2010) 207:1393407. doi: 10.1084 /jem.20100045 functional Treg subsets are expected to elaborate personalized Treg therapies in the context of auto-immunity, inflammation, and regenerative medicine.

\section{AUTHOR CONTRIBUTIONS}

JS and MI conceived and wrote the manuscript. AB critically read and discussed the content prior to submission. All authors contributed to the article and approved the submitted version.

\section{FUNDING}

This work received funding from Excellence Initiative of AixMarseille University-A* Midex, a French Investissements d'avenir program (LTalpha-Treg to MI) and the Agence Nationale de la Recherche (grant ANR-19-CE18-0021-01, RANKLthym to MI) and was supported by institutional grants from Institut National de la Santé et de la Recherche Médicale, Centre National de la Recherche Scientifique and Aix-Marseille Université. AB was supported by a Ph.D. fellowship from the Ministère de l'Enseignement Supérieur et de la Recherche.
12. Kalekar LA, Schmiel SE, Nandiwada SL, Lam WY, Barsness LO, Zhang N, et al. $\mathrm{CD} 4+\mathrm{T}$ cell anergy prevents autoimmunity and generates regulatory $\mathrm{T}$ cell precursors. Nat Immunol. (2016) 17:304-14. doi: 10.1038/ni.3331

13. Schlenner SM, Weigmann B, Ruan Q, Chen Y, von Boehmer H. Smad3 binding to the Foxp3 enhancer is dispensable for the development of regulatory T cells with the exception of the gut. J Exp Med. (2012) 209:152935. doi: 10.1084/jem.20112646

14. Samstein RM, Josefowicz SZ, Arvey A, Treuting PM, Alexander R. Extrathymic generation of regulatory $\mathrm{T}$ cells in placental mammals mitigates maternal-fetal conflic. Cell. (2012) 150:29-38. doi: 10.1016/j.cell.2012.05.031

15. Josefowicz SZ, Niec RE, Kim HY, Treuting P, Chinen T, Zheng Y, et al. Extrathymically generated regulatory $\mathrm{T}$ cells control mucosal TH2 inflammation. Nature. (2012) 482:395-9. doi: 10.1038/nature10772

16. Ohnmacht C, Park J-H, Cording S, Wing JB, Atarashi K, Obata $\mathrm{Y}$, et al. MUCOSAL IMMUNOLOGY. The microbiota regulates type 2 immunity through $\mathrm{ROR} \mathrm{t}^{+} \mathrm{T}$ cells. Science. (2015) 349:989-93. doi: 10.1126/science.aac4263

17. Lathrop SK, Bloom SM, Rao SM, Nutsch K, Lio C-W, Santacruz N, et al. Peripheral education of the immune system by colonic commensal microbiota. Nature. (2011) 478:250-4. doi: 10.1038/nature10434

18. Miller J. Effect of neonatal thymectomy on the immunological responsiveness of the mouse. Proc $R$ Soc Lond B Biol Sci. (1962) 156:415-28. doi: 10.1098/rspb.1962.0048

19. Nishizuka Y, Sakakura T. Thymus and reproduction: sex-linked dysgenesia of the gonad after neonatal thymectomy in mice. Science. (1969) 166:7535. doi: 10.1126/science.166.3906.753

20. Sakaguchi S, Fukuma K, Kuribayashi K, Masuda T. Organ-specific autoimmune disease induced in mice by elimination of $\mathrm{Y}$ cell subset. Evidence for the active participation of $\mathrm{T}$ cells in natural self-tolerance; deficit of a T cell subset as a possible cause of autoimmune disease. J Exp. (1985) 161:72-87. doi: 10.1084/jem.161.1.72

21. Sakaguchi S, Sakaguchi N, Asano M, Itoh M, Toda M. Immunologic self-tolerance maintained by activated $\mathrm{T}$ cells expressing IL-2 receptor alpha-chains (CD25). Breakdown of a single mechanism of selftolerance causes various autoimmune diseases. J Immunol. (1995) 155:1151-64. doi: 10.4049/jimmunol.0903301

22. Ohki H, Martin C, Corbel C, Coltey M, Le Douarin NN. Tolerance induced by thymic epithelial grafts in birds. Science. (1987) 237:10325. doi: $10.1126 /$ science. 3616623 
23. Modigliani Y, Thomas-vaslintt V, Bandeira A, Colteyt M, Douarint NMLE, Coutinho A, et al. Lymphocytes selected in allogeneic thymic epithelium mediate dominant tolerance toward tissue grafts of the thymic epithelium haplotype. Proc Natl Acad Sci USA. (1995) 92:75559. doi: 10.1073/pnas.92.16.7555

24. Sakaguchi S, Takahashi T, Nishizuka Y. Study on cellular events in postthymectomy autoimmune oophoritis in mice II. Requirement of Lyt-1 cells in normal female mice for the prevention of oophoritis. J Exp Med. (1982) 156:1577-86. doi: 10.1084/jem.156.6.1577

25. Owen DL, Sjaastad LE, Farrar MA. Regulatory $T$ cell development in the thymus. J Immunol. (2019) 203:2031-41. doi: 10.4049/jimmunol.1900662

26. Klein L, Robey EA, Hsieh CS. Central CD4+T cell tolerance: deletion versus regulatory T cell differentiation. Nat Rev Immunol. (2019) 19:718. doi: 10.1038/s41577-018-0083-6

27. Perry JSA, Lio CWJ, Kau AL, Nutsch K, Yang Z, Gordon JI, et al. Distinct contributions of Aire and antigen-presenting-cell subsets to the generation of self-tolerance in the thymus. Immunity. (2014) 41:41426. doi: 10.1016/j.immuni.2014.08.007

28. Jordan MS, Boesteanu A, Reed AJ, Petrone AL, Holenbeck AE, Lerman MA, et al. Thymic selection of $\mathrm{CD} 4+\mathrm{CD} 25+$ regulatory $\mathrm{T}$ cells induced by an agonist self-peptide. Nat Immunol. (2001) 2:301-6. doi: 10.1038/86302

29. Romagnoli P, Hudrisier D, van Meerwijk JPM. Preferential recognition of self antigens despite normal thymic deletion of CD4+CD25+ regulatory T cells. $J$ Immunol. (2002) 168:1644-8. doi: 10.4049/jimmunol.168.4.1644

30. Hsieh C, Zheng Y, Liang Y, Fontenot JD, Rudensky AY. An intersection between the self-reactive regulatory and nonregulatory $\mathrm{T}$ cell receptor repertoires. Nat Immunol. (2006) 7:401-10. doi: 10.1038/ni1318

31. Pacholczyk R, Ignatowicz H, Kraj P, Ignatowicz L. Origin and T cell receptor diversity of Foxp3+CD4+CD25+ T cells. Immunity. (2006) 25:24959. doi: 10.1016/j.immuni.2006.05.016

32. Hsieh CS, Liang Y, Tyznik AJ, Self SG, Liggitt D, Rudensky AY. Recognition of the peripheral self by naturally arising CD25+CD4+ T cell receptors. Immunity. (2004) 21:267-77. doi: 10.1016/j.immuni.2004.07.009

33. Lee H, Bautista JL, Scott-browne J, Mohan JF, Hsieh C. A broad range of selfreactivity drives thymic regulatory $\mathrm{T}$ cell selection to limit responses to self. Immunity. (2012) 37:475-86. doi: 10.1016/j.immuni.2012.07.009

34. Malhotra D, Linehan JL, Dileepan T, Lee YJ, Purtha WE, Lu JV, et al. Tolerance is established in polyclonal CD4+T cells by distinct mechanisms, according to self-peptide expression patterns. Nat Immunol. (2016) 17:18795. doi: 10.1038/ni.3327

35. Legoux FP, Lim JB, Cauley AW, Dikiy S, Ertelt J, Mariani TJ, et al. CD4+T cell tolerance to tissue-restricted self antigens is mediated by antigenspecific regulatory $\mathrm{T}$ cells rather than deletion. Immunity. (2015) 43:896908. doi: 10.1016/j.immuni.2015.10.011

36. Salomon B, Lenschow DJ, Rhee L, Ashourian N, Singh B, Sharpe A, et al. B7/CD28 Costimulation is essential for the homeostasis of the CD4+CD25+ immunoregulatory $\mathrm{T}$ cells that control autoimmune diabetes. Immunity. (2000) 12:431-40. doi: 10.1016/S1074-7613(00)80195-8

37. Vang KB, Yang J, Pagán AJ, Li L-X, Wang J, Green JM, et al. Cutting edge: CD28 and c-Rel-dependent pathways initiate regulatory T cell development. J Immunol. (2010) 184:4074-7. doi: 10.4049/jimmunol.0903933

38. Lio C-WJ, Dodson LF, Deppong CM, Hsieh C-S, Green JM. CD28 facilitates the generation of Foxp ${ }^{-}$cytokine responsive regulatory $\mathrm{T}$ cell precursors. $J$ Immunol. (2010) 184:6007-13. doi: 10.4049/jimmunol.1000019

39. Mahmud SA, Manlove LS, Schmitz HM, Xing Y, Wang Y, Owen DL, et al. Costimulation via the tumor-necrosis factor receptor superfamily couples TCR signal strength to the thymic differentiation of regulatory T cells. Nat Immunol. (2014) 15:473-81. doi: 10.1038/ni.2849

40. Tai X, Michelle C, Feigenbaum L, Singer A. CD28 costimulation of developing thymocytes induces Foxp3 expression and regulatory $\mathrm{T}$ cell differentiation independently of interleukin 2. Nat Immunol. (2005) 6:15262. doi: 10.1038/ni1160

41. Lio CWJ, Hsieh CS. A two-step process for thymic regulatory $\mathrm{T}$ cell development. Immunity. (2008) 28:10011. doi: 10.1016/j.immuni.2007.11.021

42. Burchill MA, Yang J, Vogtenhuber C, Blazar BR, Farrar MA. IL-2 receptor-dependent STAT5 activation is required for the development of Foxp $^{+}$regulatory $\mathrm{T}$ cells. J Immunol. (2007) 178:280-90. doi: 10.4049/jimmunol.178.1.280

43. Burchill MA, Yang J, Vang KB, Moon JJ, Chu HH, Lio CW, et al. Linked $\mathrm{T}$ cell receptor and cytokine signaling govern the development of the regulatory $\mathrm{T}$ cell repertoire. Immunity. (2008) 28:112-21. doi: 10.1016/j.immuni.2007.11.022

44. Fontenot JD, Rasmussen JP, Gavin MA, Rudensky AY. A function for interleukin 2 in Foxp3-expressing regulatory T cells. Nat Immunol. (2005) 6:1142-51. doi: 10.1038/ni1263

45. Malek TR, Yu A, Vincek V, Scibelli P, Kong L. CD4 regulatory $\mathrm{T}$ cells prevent lethal autoimmunity in IL-2Rb-deficient mice: implications for the nonredundant function of IL-2. Immunity. (2002) 17:167-78. doi: 10.1016/S1074-7613(02)00367-9

46. Marshall D, Sinclair C, Tung S, Marshall D, Sinclair C, Tung S, et al. Differential requirement for IL-2 and IL-15 during bifurcated development of thymic regulatory T cells. J Immunol. (2014) 193:552533. doi: 10.4049/jimmunol.1402144

47. Vang KB, Yang J, Mahmud SA, Burchill MA, Vegoe AL, Michael A, et al. IL$2,-7$, and -15 , but not thymic stromal lymphopoeitin, redundantly govern CD4+Foxp3+regulatory T cell development. J Immunol. (2008) 181:328590. doi: 10.4049/jimmunol.181.5.3285

48. Tai X, Erman B, Alag A, Mu J, Kimura M, Katz G, et al. Foxp3 transcription factor is proapoptotic and lethal to developing regulatory $\mathrm{T}$ cells unless counterbalanced by cytokine survival signals. Immunity. (2013) 38:111628. doi: 10.1016/j.immuni.2013.02.022

49. Weist BM, Kurd N, Boussier J, Chan SW, Robey EA. Thymic regulatory T cell niche size is dictated by limiting IL-2 from antigen-bearing dendritic cells and feedback competition. Nat Immunol. (2015) 16:635-41. doi: 10.1038/ni.3171

50. Owen DL, Mahmud SA, Vang KB, Kelly RM, Blazar BR, Smith KA, et al. Identification of cellular sources of IL-2 needed for regulatory $\mathrm{T}$ cell development and homeostasis. J Immunol. (2018) 200:392633. doi: 10.4049/jimmunol.1800097

51. Hemmers S, Schizas M, Azizi E, Dikiy S, Zhong Y, Feng Y, et al. IL-2 production by self-reactive CD4 thymocytes scales regulatory $\mathrm{T}$ cell generation in the thymus. J Exp Med. (2019) 216:2466-78. doi: 10.1084/jem.20190993

52. Cui G, Hara T, Simmons S, Wagatsuma K, Abe A, Miyachi H, et al. Characterization of the IL-15 niche in primary and secondary lymphoid organs in vivo. Proc Natl Acad Sci USA. (2013) 111:191520. doi: $10.1073 /$ pnas.1318281111

53. White AJ, Jenkinson WE, Cowan JE, Parnell SM, Bacon A, Jones ND, et al. An essential role for medullary thymic epithelial cells during the intrathymic development of invariant NKT cells. J Immunol. (2014) 192:265966. doi: 10.4049/jimmunol.1303057

54. Owen DL, Mahmud SA, Sjaastad LE, Williams JB, Spanier JA, Simeonov DR, et al. Thymic regulatory $\mathrm{T}$ cells arise via two distinct developmental programs. Nat Immunol. (2019) 20:195-205. doi: 10.1038/s41590-018-0289-6

55. Ferreira LMR, Muller YD, Bluestone JA, Tang Q. Next-generation regulatory $\mathrm{T}$ cell therapy. Nat Rev Drug Discov. (2019) 18:74969. doi: 10.1038/s41573-019-0041-4

56. Park J-E, Botting RA, Conde CD, Popescu D-M, Lavaert M, Kunz DJ, et al. A cell atlas of human thymic development defines $\mathrm{T}$ cell repertoire formation. Science. (2020) 367:eaay3224. doi: 10.1101/2020.01.28.911115

57. Schuster M, Plaza-sirvent C, Matthies A, Heise U, Jeron A, Bruder D, et al. c-REL and $I \kappa B_{N S}$ govern common and independent steps of regulatory $T$ cell development from novel CD122-expressing pre-precursors. J Immunol. (2017) 199:920-30. doi: 10.4049/jimmunol.1600877

58. Schuster M, Plaza-sirvent C, Visekruna A, Huehn J, Schmitz I. Generation of Foxp3+CD25- regulatory T-cell precursors requires c-rel and $\mathrm{I}_{\kappa} \mathrm{B}_{\mathrm{NS}}$. Front Immunol. (2019) 10:1-6. doi: 10.3389/fimmu.2019.01583

59. Yu W, Nagaoka H, Jankovic M, Misulovin Z, Suh H, Rolink A, et al. Continued RAG expression in late stages of B cell development and no apparent reinduction after immunization. Nature. (1999) 400:682-7. doi: 10.1038/23287

60. Bending D, Martín PP, Paduraru A, Ducker C, Marzaganov E, Laviron $\mathrm{M}$, et al. A timer for analyzing temporally dynamic changes in transcription during differentiation in vivo. J Cell Biol. (2018) 217:2931-50. doi: $10.1083 /$ jcb. 201711048 
61. Wyss L, Stadinski BD, King CG, Schallenberg S, McCarthy NI, Lee JY, et al. Affinity for self antigen selects Treg cells with distinct functional properties. Nat Immunol. (2016) 17:1093-101. doi: 10.1038/ni.3522

62. Bosco N, Agenes F, Rolink AG, Ceredig R. Peripheral T cell lymphopenia and concomitant enrichment in naturally arising regulatory $\mathrm{T}$ cells: the case of the pre-Talpha gene-deleted mouse. J Immunol. (2006) 177:501423. doi: 10.4049/jimmunol.177.8.5014

63. Zhan Y, Bourges D, Dromey JA, Harrison LC, Lew AM. The origin of thymic CD4+CD25+regulatory $\mathrm{T}$ cells and their co-stimulatory requirements are determined after elimination of recirculating peripheral CD4+cells. Int Immunol. (2007) 19:455-63. doi: 10.1093/intimm/dxm010

64. Boursalian TE, Golob J, Soper DM, Cooper CJ, Fink PJ. Continued maturation of thymic emigrants in the periphery. Nat Immunol. (2004) 5:418-25. doi: 10.1038/ni1049

65. McCaughtry TM, Wilken MS, Hogquist KA. Thymic emigration revisited. J Exp Med. (2007) 204:2513-20. doi: 10.1084/jem.20070601

66. Thiault N, Darrigues J, Adoue V, Gros M, Binet B, Perals C, et al. Peripheral regulatory $\mathrm{T}$ lymphocytes recirculating to the thymus suppress the development of their precursors. Nat Immunol. (2015) 16:62834. doi: 10.1038/ni.3150

67. Cowan JE, McCarthy NI, Anderson G. CCR7 controls thymus recirculation, but not production and emigration, of Foxp3+T cells. Cell Rep. (2016) 14:1041-8. doi: 10.1016/j.celrep.2016.01.003

68. Yang EJ, Zou T, Leichner TM, Zhang SL, Kambayashi T. Both retention and recirculation contribute to long-lived regulatory $\mathrm{T}$-cell accumulation in the thymus. Eur J Immunol. (2014) 44:2712-20. doi: 10.1002/eji.201444529

69. Darrigues J, Santamaria JC, Galindo-Albarrán A, Robey EA, Joffre OP, Meerwijk JPM, et al. Robust intrathymic development of regulatory T cells in young NOD mice is rapidly restrained by recirculating cells. Eur J Immunol. (2020). doi: 10.1002/eji.202048743. [Epub ahead of print].

70. Cowan JE, Baik S, McCarthy NI, Parnell SM, White AJ, Jenkinson WE, et al. Aire controls the recirculation of murine Foxp3+regulatory T-cells back to the thymus. Eur J Immunol. (2018) 48:844-54. doi: 10.1002/eji.201747375

71. Perniola R. Twenty years of AIRE. Front Immunol. (2018) 9:98. doi: 10.3389/fimmu.2018.00098

72. Peligero-Cruz C, Givony T, Sebé-Pedrós A, Dobeš J, Kadouri N, Nevo S, et al. IL18 signaling promotes homing of mature Tregs into the thymus. Elife. (2020) 9:e58213. doi: 10.7554/eLife.58213

73. Yang S, Fujikado N, Kolodin D, Benoist C, Mathis D. Regulatory T cells generated early in life play a distinct role in maintaining self-tolerance. Science. (2015) 348:589-94. doi: 10.1126/science.aaa7017

74. McCarthy NI, Cowan JE, Nakamura K, Bacon A, Baik S, White AJ, et al. Osteoprotegerin-mediated homeostasis of rank+thymic epithelial cells does not limit Foxp3+regulatory $\mathrm{T}$ cell development. J Immunol. (2015) 195:2675-82. doi: 10.4049/jimmunol. 1501226
75. Hikosaka Y, Nitta T, Ohigashi I, Yano K, Ishimaru N, Hayashi Y, et al. The cytokine RANKL produced by positively selected thymocytes fosters medullary thymic epithelial cells that express autoimmune regulator. Immunity. (2008) 29:438-50. doi: 10.1016/j.immuni.2008.06.018

76. Malchow S, Leventhal DS, Lee V, Nishi S, Socci ND, Savage PA. Aire enforces immune tolerance by directing autoreactive $\mathrm{T}$ cells into the regulatory $\mathrm{T}$ cell lineage. Immunity. (2016) 44:1102-13. doi: 10.1016/j.immuni.2016.02.009

77. Khan IS, Mouchess ML, Zhu ML, Conley B, Fasano KJ, Hou Y, et al. Enhancement of an anti-tumor immune response by transient blockade of central $\mathrm{T}$ cell tolerance. J Exp Med. (2014) 211:7618. doi: 10.1084/jem.20131889

78. Irla M, Hugues S, Gill J, Nitta T, Hikosaka Y, Williams IR, et al. Autoantigen-specific interactions with $\mathrm{CD} 4+$ thymocytes control mature medullary thymic epithelial cell cellularity. Immunity. (2008) 29:45163. doi: 10.1016/j.immuni.2008.08.007

79. Lopes N, Sergé A, Ferrier P, Irla M. Thymic crosstalk coordinates medulla organization and T-cell. Front Immunol. (2015) 6:365. doi: 10.3389/fimmu.2015.00365

80. Desanti GE, Cowan JE, Baik S, Parnell SM, White AJ, Penninger JM, et al. Developmentally regulated availability of RANKL and CD40 ligand reveals distinct mechanisms of fetal and adult cross-talk in the thymus medulla. J Immunol. (2012) 189:5519-26. doi: 10.4049/jimmunol.12 01815

81. Irla M. RANK signaling in the differenciation and regeneration of thymic epithelial cells. Front Immunol. (2021) 11:3592. doi: 10.3389/fimmu.2020.623265

82. Yin C, Pei XY, Shen H, Gao YN, Sun XY, Wang W, et al. Thymic homing of activated CD4+T cells induces degeneration of the thymic epithelium through excessive RANK signaling. Sci Rep. (2017) 7:112. doi: 10.1038/s41598-017-02653-9

83. Nikolouli E, Elfaki Y, Herppich S, Schelmbauer C, Delacher M, Falk $\mathrm{C}$, et al. Recirculating IL-1R $2+$ mtecs fi ne-tune intrathymic Treg development under inflammatory conditions. Cell Mol Immunol. (2020) 18:182-93. doi: 10.1038/s41423-019-0352-8

Conflict of Interest: The authors declare that the research was conducted in the absence of any commercial or financial relationships that could be construed as a potential conflict of interest.

Copyright (c) 2021 Santamaria, Borelli and Irla. This is an open-access article distributed under the terms of the Creative Commons Attribution License (CC BY). The use, distribution or reproduction in other forums is permitted, provided the original author(s) and the copyright owner(s) are credited and that the original publication in this journal is cited, in accordance with accepted academic practice. No use, distribution or reproduction is permitted which does not comply with these terms. 